\title{
GEOPHYSICAL STUDY OF SUBMARINE GEOLOGY*
}

\author{
By Dr. E. C. Bullard, \\ Smithsonian Research Fellow of the Royal Society
}

$\mathrm{T}$ WO thirds of the earth's surface are covered by water. Our direct knowledge of the geology of this area is derived from samples obtained by lowering grabs and similar instruments on to the sea bottom. To realize the inadequacy of this evidence we have only to consider how little we should know of the past history and structure of the continents if our information were confined to that which could be obtained from a few thousand samples of surface soil collected from points scattered over the earth. In recent years a number of methods have been developed for finding out something about the form, constitution, and structure of the rocks hidden beneath the sea. These methods form part of geophysics, that is to say, they involve the application of techniques derived from physics to solve problems about the earth.

By merely examining a map of a piece of country, it is often possible to say something of its more recent history, for the form of the surface is a consequence of its constitution and history. Further, an adequate map is an essential basis on which to plot lithological and structural information.

The first problem of submarine geology is therefore to devise methods of making maps of the ocean with a detail and accuracy comparable with the maps of land areas. In doing this, two things have to be determined, $(a)$ the depth of the sea, and $(b)$ the position at which the depth is measured. The measurement of depth is easily and rapidly carried out with the echo sounder. In the type of instrument developed by the Admiralty, a pulse of supersonic sound is produced by a magnetostriction oscillator attached to the bottom of the ship. The sound travels to the bottom of the sea where part of it is reflected. The reflected part returns to the oscillator, which acts as a microphone and records the arrival of the pulse on a moving piece of paper. In this way a continuous record of the time taken for the echo to return can be made, and if the velocity of sound in sea water is known, this gives a continuous profile of the route over which the ship has steamed.

The determination of the position of the ship when the sounding is made is considerably more difficult if the ship is out of sight of land. Wind and currents soon cause a course steered by dead

* Substance of a Friday Evening Discourse delivered at the Royal Institution on April 26. reckoning to become uncertain by several miles, and astronomical position finding can involve considerable errors and is not always possible. To overcome these difficulties the method of 'taut wire' control has been developed. In this method a number of mutually intervisible buoys are laid, and the distances between them determined by running out piano wire from a drum on the ship and measuring the length run out by passing it over a measuring sheave. This method gives an accuracy of the order of one in a thousand, but is too elaborate to use for any purpose beyond the fixing of the positions of a few control points for use in the detailed survey. The position of the ship when taking a sounding may be found by observations on three buoys in known positions, but this requires good visibility and a close network of buoys.

To obviate this difficulty, the United States Coast and Geodetic Survey has developed the method of 'radio-acoustic ranging'. A small bomb is thrown from the ship the position of which it is desired to determine. The sound from the bomb travels through the sea and actuates a microphone suspended from a buoy. The microphone is con. nected to a wireless transmitter in the buoy which signals the instant of arrival of the sound. Thus, if the original explosion and the arrival of the wireless signal are recorded on the ship, the time interval between them will give a measure of the distance of the ship from the buoy. If there are two or more such buoys in known positions, the position of the ship may be found with an accuracy of a few tenths of a mile. In the practical application of this method, a bomb is thrown overboard about every six minutes, so that the position of the ship is found about once every mile. In the past few years, the greater part of the waters around the United States have been mapped by such methods out to the thousand-fathom line.

The seas around the continents almost invariably consist of a comparatively shallow 'Continental Shelf' sloping very gently to 100 fathoms in a distance of 50-200 miles, that is, with an average slope of a tenth to a fortieth of a degree. At about the 100-fathom line, the slope suddenly steepens to about $4^{\circ}$, and in a few miles the sea deepens to $1,000-2,000$ fathoms. The American surveys give a map of this area on a scale of two miles to one inch. These maps have brought to . light several remarkable features. First, there is 
a very sharp demarcation between the shelf and the slope at its outer edge; when sailing outwards from the continent the sudden change of slope is very conspicuous on the echo sounder, and its start can be placed on the record within a few hundred yards. Secondly, the sloping edge of the shelf is cut into by a remarkable series of submarine valleys. The existence off the coast of America and elsewhere of these valleys has been known for many years, but it is only recently that much attention has been paid to them. They are steep-sided features generally with flat bottoms, often lying several thousand feet below the level of the sea bottom on each side.

The origin of these features has been the subject of considerable controversy. It has been maintained that they were cut by rivers at a time when the level of the sea was much lower than at present. The recent surveys, which show the valleys to extend to the 1,000-fathom line, make the necessary lowering of the sea so great that this hypothesis must be abandoned. The difficulties of supposing the land to have been raised 6,000 ft. and lowered again are no less severe. Such a change must have left its mark on the flat-lying sediments of the coastal plain and have caused changes in the drainage which would be apparent in the present-day physiography. We are therefore compelled to believe that the valleys were formed under the sea. Unfortunately, very little is known of submarine erosional processes, largely owing to the lack of detailed surveys and to our scanty knowledge of the nature of the rocks forming the submarine topography.

It is, in fact, not possible to discuss these questions profitably without more information about the nature of the rocks forming the sea floor. Cores up to ten feet long have recently been secured from these rocks by firing a tube into the bottom from a gun lowered from a ship. Such methods are of great importance, but we can scarcely hope to obtain by their aid information about rocks more than a few tens of feet below the bottom of the sea. To penetrate deeper, indirect methods must be used. The most promising of these is the seismic method. In this, charges of explosive are detonated on the sea bottom and the elastic waves produced are recorded by seismographs also placed on the bottom. When an explosion is made, waves spread out from it in all directions, and from the time taken for the waves to travel a known distance their velocity may be found and an indication obtained of the nature of the rock through which they have travelled.

Reflexions of waves from the interfaces between hard and soft rock may also be observed. If a layer of a soft rock in which the velocity of the waves is relatively slow overlies a hard rock in which the velocity is high, it is possible for a wave to travel down to the hard rock, along in it, and up again in a shorter time than it can traverse the direct path through the soft rock. It is on the observation of such 'refracted' waves that the work done at sea depends. Measurements have been made off the eastern coast of the United States, and to the west of the British Isles, with broadly similar results. In the case of the British Isles, igneous and well-consolidated sedimentary rocks are exposed on land, and measurements at sea near the shore show them to be covered by only a few feet of recent sediments. On going farther from shore the thickness of the sediments increases steadily until at the 100 -fathom line about 150 miles out to sea, the hard rocks are buried beneath more than $8,000 \mathrm{ft}$. of sediments. Beyond this it was not possible to go with the facilities available, but if the surface of the hard rock be extrapolated for a few miles, it runs over smoothly into the floor of the deep ocean.

It therefore seems that the Continental Shelf is a mass of sediments lying on a gently sloping surface of solid rock, and that the edge of the shelf is simply the edge of the sediments and does not represent a fault line dividing the ocean from the continent. This suggests that the Continental Shelf is growing seaward by deposition of the sediments worn from the land, the level of its surface being determined by the level at which the sediments can just rest without being disturbed by currents and wave motion. If this picture be correct, a particle of sediment brought down by a river is washed hither and thither on the sea floor until at last it comes to rest beyond the edge of the Shelf in water so deep and still that it can no longer be moved. It is probable that such a process would result in the deposition of sediments at an angle too steep for stability and that landslips would occur producing the jumbled topography typical of the edge of the Shelf. Great masses of rocks showing signs of contortion while plastic would also be produced; such rocks have been found in many parts of the world, and may well have been produced in this way.

Measurements of gravity over the Continental Shelf should also give useful information. Unfortunately, only a few measurements have so far been made; these show, rather unexpectedly, that the sediments are in isostatic equilibrium; that is to say, the crust has sunk under their weight, until it is in equilibrium.

Present technique can give much information about the geology of the shallow seas, but these form only a small proportion of the whole. The outstanding problem is to develop accurate methods of position-finding far out at sea, so that accurate surveys can be carried out in mid-ocean, 
and to develop a variation of the seismic method that can be used in deep water. A start has been made with this work, and when conditions again allow experiments at sea, there is little doubt that rapid progress will be made. The problems to be studied are of great importance for geology. The mapping of a section of the mid-Atlantic Ridge, for example, together with determinations of the velocities of elastic waves in it, could not fail to yield results of great interest. We know already that it includes features which are on a scale comparable with the Himalayas, and such a survey would indicate whether these mountains were a folded range that had never been exposed to denudation, a sunken land mass, or a system of submarine volcanoes. The major rival geological theories, such as the permanence of ocean basins and Continental Drift, involve theories about the oceans. As they are derived almost entirely from data obtained on land, the study of the other two thirds of the earth's surface may be expected to be illuminating.

\section{BORON IN AGRICULTURAL AND HORTICULTURAL PRACTICE}

$\mathrm{D}^{\mathrm{t}}$ URING the past year some three hundred and fifty papers and articles relating to the uses of boron compounds in agriculture and horticulture were published in twenty-one different countries. Nearly half of these contributions were made in the United States, where the rapidly growing interest in the subject was particularly marked. According to a recent report, boron investigations covering a wide range of soils and crops are now in progress in at least twenty-six American States. Important among the new findings published in the United States during the year was the efficacy of applications of boron to the soil in controlling canker disease, also termed girdle or internal black spot, of table or canning beet. The disorder appears to be closely related to heart rot, the wellknown boron deficiency disease of sugar beet and mangolds. Canker is said to be very prevalent and of considerable economic importance in the canning beet growing districts in the States of New York, Michigan, Oregon and Wisconsin. Its presence has also been observed in Washington State.

The beneficial use of boron on daffodils was reported from North Carolina, and further advance was made in New York State in the study of internal bark necrosis of apple trees and its control by the application of boron. A first progress report on drouth spot of prunes was also issued in the latter State. The first recorded instance of boron deficiency in cabbage and related crops, under field conditions, was reported from Wisconsin. The disorder, an internal breakdown of the stem in the region of the core, was largely controlled by the application of boron. In Florida, the condition of citrus trees in several groves is considered to suggest a lack of boron. An investigation of this possibility has been begun. An apparently new disorder of tomato plants, experienced in New Jersey, and characterized by a form of yellowing of the leaves, was controlled by suitable applications of boron. In the same State, the first recorded symptoms of boron deficiency in roses grown in sand cultures were described.

Three important reviews of literature were published in the United States during the year. The first supplement to the American Potash Institute's Bibliography of Literature "Boron as a Plant Nutrient" was issued in May and listed 171 papers reviewed during the period July to December, 1938. The Chilean Nitrate Educational Bureau Inc., New York, published the third edition of its well-known "Bibliography of References to Literature on the Minor Elements". This lists 449 papers relating to boron. A booklet entitled "Boron in Agriculture", published by the Pacific Coast Borax Company, New York, presents a concise and well-illustrated review of work conducted in the United States and Canada.

In New Zealand and Australia the list of crops which may suffer from boron deficiency under field. conditions was also extended. In the former country, workers at the Cawthron Institute found that a disorder of apricot fruits, which is sometimes prevalent in the orchards there, is due to lack of boron and can be controlled by the addition of boron to the soil or by spraying it on to the tree. The disorder in question has been termed 'brown spotting'. Further investigation of the subject is in progress. In Queensland, Australia, a condition of young pineapple plants, known as 'crookneck' (so called on account of the manner in which the heart leaves are twisted) was largely controlled by spraying the plants with boron. Progress was reported from New South Wales concerning the investigations being conducted there on needle fusion of pines. The application of boron to diseased trees has given complete or partial recovery in some cases, but in others has so far been without result. This disorder of pines also received further attention in Great Britain, where it was shown that the leaves of affected trees contained 